Lloyd, E. M. H. (1936). F. agric. Econ. Soc, 4, 89.

Lloyd, E. M. H. (1953). F. agric. Econ. Soc. ro, 174.

Lyle, P. (I950). F. R. statist. Soc. Ser. A, Ir3, 53 I.

Ministry of Agriculture, Fisheries and Food (r962). Bd Trade $\mathcal{F}_{\text {. }} \mathbf{1 8}_{\mathbf{3}}$, i.

Ministry of Agriculture, Fisheries and Food (r963). Bd Trade 7. r85, 296.

Ministry of Agriculture, Fisheries and Food: National Food Survey Committee (1962). Domestic Food Consumption and Expenditure: 1960. London: H. M. Stationery Office.

Ministry of Agriculture, Fisheries and Food: National Food Survey Committee ( I963). Domestic Food Consumption and Expenditure: 1961. London: H. M. Stationery Office.

Ministry of Health: Advisory Committee on Nutrition (1937). First Report. London: H. M. Stationery Office.

Ministry of Labour (1963). Family Expenditure Survey: 1962. London: H.M. Stationery Office.

Royal Society Committee (1917). The Food Supply of the United Kingdom. Cd. 842 r. London: H.M. Stationery Office.

Wadsworth, G. R. \& McKenzie, J. C. (1963). Nuir. Abstr. Rev. 33, 327.

\title{
Carbohydrate consumption and diabetes
}

\section{By Joan B. Walker, Diabetic Department, Leicester Royal Infirmary}

While research into carbohydrate metabolism and the action of insulin is increasing, clinicians continue to treat diabetes by regulating the intake of carbohydrate. It is surprising that we achieve the present degree of success because one is bound to accept a multifactorial theory of aetiology of the disease. What part carbohydrate consumption may play must be correlated with such factors as sex, age, heredity, physique, hormonal adjustment, social status, energy expenditure, stress, and finally dietary habits. The increasing amount of information that is being gathered in each of these fields of study leaves us somewhat bewildered, yet we must be reaching the state of full saturation when crystallization of thought should take place.

Correction of diet is the basic therapy for all diabetics and how successful it will be depends not only on the intelligence and co-operation of the patient, but also on the experience and skilful art of the teacher.

\section{Historical note}

In retrospect, it is of interest that in the history of diabetes, essential 'management' has usually preceded investigation. Three hundred years ago, Willis advocated a reduction in carbohydrate intake as a means of bringing about an 'undernutrition cure'. Rollo ( 1796 ; quoted by Duncan, I95I) restricted his diabetic patients' diet to animal food and green vegetables. Bouchardat ( 1883 ) noted that one in twenty of the wealthy, well-fed professional class in Paris in 1875 would be found to be glycosuric. He prescribed a small diet and occasional days of fasting. This $5 \%$ of glycosuria compares with the recent figure of $4.8 \%$ that we found in 1962 in the well-fed village community of Ibstock.

It was Allen (1914) who systematized undernutrition therapy for diabetes in the belief that diabetes was a disorder of total metabolism and not of carbohydrate alone'. The late Elliot P. Joslin (Joslin, Root, White \& Marble, 1959) in Boston and Russell Wilder ( $1957^{-8}$ ) of the Mayo Clinic used Allen's diet extensively up to the 
time of the discovery of insulin in 1921 . Carbohydrate restriction and undernutrition dealt effectively with the older group of mild, overweight diabetics, but only offered a short reprieve to the young, acute, insulin-lacking diabetic. With insulin, the feeding of diabetics changed to establish better nutrition, although the experienced physician still taught that it was wiser for a diabetic to be a little below average weight. This was hard to reconcile with treatment for tuberculosis and other infections which, at that time, still took serious toll. Accurate control of carbohydrate intake was thought to be required and methods of educating the diabetic were sought. Lawrence's (1941 $a$ ) line-ration cards had an important effect on dietetic management. The constituents of different foods and equivalent amounts, most particularly of the carbohydrate content of any natural or prepared food, had to be taught to people of all grades of intelligence and education.

\section{Insulin and diet}

Quite soon it was found that there is no general correlation between insulin requirement and carbohydrate intake and that trial and error is the basis of diet and insulin planning. Although we obtain certain measurable indices on which to base therapy, so far I know of no diabetic clinic managed by a computer. The measurements we use are sex, age, height, weight, urine sugar content and blood sugar level. We can note the type of physical exercise taken daily as an average, but allowances for variations have to be made; complicating physical and pathological conditions occur, and it is impossible to predict certain emotional stress and trauma which disorganize the insulin and carbohydrate requirements. However, years of personal experience give one intuition in dealing with each case, most difficult to teach to the young house physician.

In the first io years of insulin treatment, diets were still low in carbohydrate---100 or $120 \mathrm{~g}$ daily were constantly used. (The original black line was only $5 \mathrm{~g}$.)

\section{Wartime diet}

With higher-carbohydrate diets during the war, it was found that control could be achieved without increasing the insulin, and on the advice of the Medical Research Council the Food Rationing Special Diets Advisory Committee to the Ministry of Food made excellent arrangements for diabetics. The first edition of Diabetes and Food Rationing (University College Hospital: Diabetic Clinic, r94I) became widely used, probably because the well-planned menu appealed to doctor and patient as a balanced normal type of diet of obtainable commodities, with carbohydrate values ranging from 100 to $\mathrm{I} 85 \mathrm{~g}$ (and energy values from 1200 to $2500 \mathrm{kcal}$ ). A Simple Diabetic Diet (unweighed) (card) from King's College Hospital, London, and the Diabetic A.B.C. Wartime Supplement (Lawrence, 194I $b$ ) were also very popular. These two centres undoubtedly played a big part in introducing reasonable dieting for diabetics in Britain.

\section{Free diet}

Stolte (1931) introduced the 'free' diabetic diet for the patient taking insulin. By this arrangement, the patients were not expected to learn anything about food 
values nor to test their urine, but were asked to avoid certain symptoms, e.g. hypoglycaemia, thirst, hunger, pruritus, nocturia and, of course, evidence of ketosis. This was most attractive to paediatricians who, at that time, were much concerned with having their child patients uninhibited. 'This method was followed by Lichtenstein, Tolstoi and others (Lichtenstein, I938; Tolstoi \& Weber, 1939, I940; Tolstoi, Almy \& Toscani, 1942; Tolstoi, I943). I was most interested to spend an afternoon in $195^{\circ}$ in Dr Tolstoi's clinic in New York. A proportion of his women outpatients complained of pruritus vulvae, but a dietitian, taking careful diet histories, found that those who were doing well had settled down to a carefully regulated intake of carbohydrate which they themselves had found to be comfortable.

In my clinic when taking over adolescents initially treated on free-diet lines, I find that their average insulin requirement is higher than that of the children on a primarily controlled diet, and their fluctuation between hypoglycaemia and ketosis is greater. On several occasions hypoglycaemia has occurred because the mother had exchanged egg for bread at breakfast. The report by Forsyth, Kinnear $\&$ Dunlop (195 l) from Edinburgh University, investigating the results of 'free' and 'controlled' carbohydrate diets, draws a distinction between 'exogenous' hyperglycaemia accompanying high carbohydrate intake and 'endogenous' hyperglycaemia resulting from breakdown of glycogen and tissue protein due to poor control. They thought that the high-calorie diet with 'exogenous' hyperglycaemia may be responsible for deterioration in the juvenile diabetic.

\section{Long-acting insulin}

The development of the long-acting insulins had more effect on the timing and spacing of the carbohydrate intake than on any change in total quantity. With soluble (regular) insulin, it is usually necessary to group the carbohydrate foods to follow the two injections and it is convenient to arrange for a high carbohydrate intake at breakfast, with the main evening meal taken not too late at night. When longacting insulin or a combination is given in the morning, great care is needed to space evenly small I $5-20 \mathrm{~g}$ carbohydrate snacks intermediately between the main meals, with particular reference to the peak time of insulin action which may be checked by random blood sugar estimations.

One notices an increasing frequency of deterioration in control in patients with long-duration diabetes treated with a single morning injection. By division of the dose into two so that some is given before breakfast and some before supper, often with no change in the existing diet arrangement, there is great improvement in well-being, and glycosuria ceases.

\section{Emergency treatment}

A brief note about emergency treatment by carbohydrate intake is needed. It is essential for the diabetic to carry a card stating that he is taking insulin and, should he show signs of hypoglycaemia, sugar should be given without delay. It is sometimes forgotten how important it is to follow up glucose given intravenously in this condition by a carbohydrate meal, since intravenous glucose is on its way out into the urine. 
In the reverse condition of recovery after diabetic ketosis or coma, regular small carbohydrate feeds to cover regular, e.g. 2-hourly, injections of insulin, need not always be of glucose-other forms of carbohydrate, fresh orange juice, milk or milk and egg or cereal preparation have the advantage of introducing other constituents, protein, fat, salts including potassium, and vitamins; glucose may be easy for the nurse to administer, but is not the ideal food.

\section{Oral hypoglycaemic drugs}

The introduction of the hypoglycaemic drugs given by mouth since I 955 has improved the lot of many elderly diabetics who could not be satisfactorily controlled on carbohydrate-restricted diet alone. Their blood sugar can be maintained at a more normal and steady level so that appetite is not excessive and dieting to maintain an optimum weight is less exacting on I $10-{ }^{--} 50 \mathrm{~g}$ carbohydrate. Some elderly belowweight diabetics may be enabled to regain weight on, e.g., 200-210 g carbohydrate with a total of $2000 \mathrm{kcal}$ together with Tolbutamide or Chlorpropamide.

We sometimes lose sight of the variety of carbohydrate taken by the patient once the diet has been taught. I have been horrified at times to find that no fruit is being eaten, or, at others, it has been added in abundance as an 'extra'. However, this may be seasonal, when strawberries, pears or plums are plentiful; as it is transient, overindulgence is limited, and likely to do more good than harm. It is sometimes difficult to teach that bread and potatoes, though put on the menu as basic commodities, are meant to be exchanged.

One does not have to work many years in a diabetic clinic before one knows that, although the carbohydrate intake may be the crucial factor in good control of the obese, elderly diabetic, it is not always the most serious item in the disorganization of the juvenile on insulin--stress of all kinds, hormonal imbalance, such as the menstrual fluctuation, and infection should always be considered first. Perhaps it is because we have accepted these multiple causes in aetiology and regulation of diabetes that I find a trained health visitor so eminently suited to teach new diabetics how to diet and regulate their lives. Although she may have a limited scientific training in dietetics, she knows the home background and sees where changes are needed and how they can be effected.

\section{Pre-diabetic carbohydrate intake}

It has been difficult to obtain accurate diet histories of the pre-diabetic phase, though some patients confess to a progressive increase in total food intake. One is left with the impression that the increasing national consumption of calories as sugar, in sweets, cakes, pastries, soft and alcoholic drinks in excess of normal requirements, plays a part in precipitating the onset of diabetes where there is already a genetic tendency.

Increased interest in the epidemiology of diabetes is beginning to tell us more about the natural history of the condition and its development. In the English village community in which I became interested in 1957 (Walker \& Kerridge, 196r), we were able to show that the factors $I$ have mentioned were of importance in the 
incidence of diabetes. We were disappointed, however, in our efforts to study the diet of the villagers. Such a study would merit a fully organized and equipped team for itself alone. Nevertheless, we did find out that the miners followed one of two patterns. They either partook of a high-calorie breakfast before the early morning shift and ate no more while down the pit, or they took no breakfast before leaving home and had ten or so rounds of bread as sandwiches which they consumed during the day. They returned home at about $4 \mathrm{pm}$ for tea which was in fact a full meat and vegetable dinner with a pudding or cake. Workers in other industries arrive home later but the pattern is similar. Beer drinking in the evenings is, of course, variable.

A common custom among the women is to have a cup of tea but no breakfast, then they nibble on and off all day. The children might or might not have a suitable breakfast, very rarely containing protein, but on the way to school sweets are often bought. Milk and school dinners are generally taken, but after school the ice-cream van is waiting at the gates and how much appetite there is for a cooked meal is inversely proportional to their pocket money. 'This appears to be a common habit of eating in our affluent industrial society, though one may find a few homes where there are well-spaced simple meals with a greater intake of protein and home-grown vegetables.

Precooked foods, whether tinned, dehydrated or frozen, are strongly tempting and the cake shops with their highly decorated displays are not patronized for parties only while there is money to spend.

\section{Carbohydrate and screening methods}

Such are present-day conditions in the village which we investigated twice at 5 -years interval. On each occasion a questionnaire was completed and a specimen of urine tested for glucose. When screening for diabetes it is essential to use a specimen of urine passed $\mathrm{I}$ or $2 \mathrm{~h}$ after a meal that has contained at least $50 \mathrm{~g}$ of carbohydrate. If blood sugar screening is the method employed, then it is preferable to give the $5 \circ \mathrm{g}$ carbohydrate in the form of glucose on an empty stomach. The blood is drawn $2 \mathrm{~h}$ later if a full glucose tolerance test is not feasible for any reason. In our survey we added an extra $20 \mathrm{~g}$ of sugar to the main meal of the day. How important this was is illustrated by the fact that, in the 182 glucose tolerance tests performed on the glycosurics we had found, 163 showed no sugar in the fasting urine. A negative test for sugar in fasting urine does not exclude diabetes. Nine of thirty-eight of our diabetics showed no sugar in their fasting urine and might have been missed. It is also important to ensure that there has been a full carbohydrate intake of at least $300 \mathrm{~g} /$ day for 3 or 4 days before the glucose tolerance test is made. Under these conditions it is found that there is a constant pattern of glycosuria and graded abnormality in glucose tolerance, but in 5 years a total increase in the number of established cases of diabetes has been found. We showed no abnormal incidence in child diabetics, as our population group of 5000 did not merit this. However, in the Leicester Diabetic Clinic, which serves an urban and rural population of half a million, the attendance of new diabetic children has more than doubled in ro years. It is necessary 
to keep an open mind and to remember all the possible factors listed: together with the bulge in the birth rate.

\section{The young male glycosuric}

In our survey, as in others, there was a noticeable preponderance of male glycosurics between the ages of 35 and 44 who were overweight. Can this be attributable to the fact that at 35 most young men have married, are likely to have family and occupational worries, have given up athletics and are eating more, and some are drinking more? It is well known that there is an increased incidence of married women who become diabetic over 50 years of age. They are statistically overweight, have had larger families than control studies show; they have borne more ro $\mathrm{lb}$ babies. They have had plenty of stress, and what about their food fancies? In our part of the world they are less active, doing sedentary work or part-time jobs by day and using washing machines and vacuum cleaners. All ride in motor cars.

\section{Comparison of carbohydrate intake in different communities}

It seems evident that a great deal more has yet to be done in examination of the well-being of our affluent society in Britain and to compare it with less-sophisticated communities. Much interest has been taken in diabetes in tropical countries. The condition has been well recorded in India for 2000 years (Tulloch, I962). 'The diets of the working classes are known to be high in carbohydrate and low in protein and fat, but accurate measurements of the constitution in its relation to the incidence of diabetes are not available with any statistical reliability. It is noted that juvenile diabetes is rare; the mild chronic form which we associate with obesity, insulin resistance and absence of ketosis occurring in the elderly seems to occur at an earlier age in those countries where the expectation of life is reduced, although obesity may not be manifest. Is this due to greater physical activity, reduction of fat in the diet, or what is the explanation? One has to remember that the leaves of local plants are eaten in many parts of India. Some have hypoglycaemic properties and may counteract the high carbohydrate intake, but only limited pharmacological study has been made on them so far. It is also possible that they may induce insulin resistance (Cosnett, 1959). My small experience in treating Indians in England would tend to support this view. Tulloch (1962) has reviewed the epidemiology of diabetes in the tropics but he is not able to give great detail about diet in its relation to the factors in which we are interested. In recent conversation with Dr Tony Mitchell while our house physician from South Africa, I was told that the poor Bantu live on maize, with hardly any other source of protein than beans. Since the beginning of this century, they have moved in and out of the towns looking for work when their diet is almost entirely restricted to bread and beer--until, or unless, they return to their kraals. They grow fat and are malnourished, but any attempt to investigate the incidence of diabetes has been in selected groups because of the difficulty in following a natural community as a whole (Politzer, Hardigger \& Schneider, 1960; Seftel \& Abrams, 1960). However, this seems to be the obvious next field for detailed epidemiological study that might shed light on how far the constituents of the diet and their 
qualitative and quantitative relationship to each other and the total calorie intake affect the incidence of diabetes.

\section{Example of the well-trained diabetic}

Well-trained diabetics might do much in imparting their practical knowledge of food values to the rest of the community to bring about an economic level of good nutrition such as we experienced in Britain during the war. The regulation of a balanced diet in an affluent society needs self-control and it is not going too far to say that the diabetic's diet should be considered the normal arrangement and not a special diet at all.

\section{REFERENCES}

Allen, F. M. (1914). F. Amer. med. Ass. 63, 939.

Bouchardat, A. (1883). De la Glycosurie ou Diabète Sucré, p. I80. Paris.

Cosnett, J. E. (1959). Brit. med. 7. i, 187 .

Duncan, G. G. (195I). Diabetes Mellitus, p. 13. Philadelphia and London: W. B. Saunders Company. Forsyth, C. C., Kinnear, T. W. G. \& Dunlop, D. M. (I951). Brit. med. F. i, 1095.

Joslin, E. P., Root, H. F., White, P. \& Marble, A. (1959). The Treatment of Diabetes Mellitus. London: Henry Kimpton.

Keen, H. (1964). Proc. R. Soc. Med. 57, 200.

Lawrence, R. D. (I94Ia). A Simple Diabetic Diet (Unweighed). London: H. K. Lewis \& Co. Ltd.

Lawrence, R. D. (I94Ib). The Diabetic ABC Wartime Supplement. London: H. K. Lewis \& Co. Ltd.

Lichtenstein, A. (1938). F. Paediat. 12, 183.

Politzer, W. M., Hardigger, B. \& Schneider, T. (1960). Brit. med. F. i, 615.

Seftel, H. C. \& Abrams, G. J. (1960). Brit. med. F. i, 1207.

Stolte, K. (1931). Med. Klinik, 27, 831 .

Tolstoi, E. (1943). Amer. F. dig. Dis. ro, 247.

Tolstoi, E., Almy, T. P. \& Toscani, V. (1942). Ann. intern. Med. 16, 893.

Tolstoi, E. \& Weber, F. C. Jr. (1939). Arch. intern. Med. 64, 9 I.

Tolstoi, E. \& Weber, F. C. Jr. (1940). Arch. intern. Med. 66, 670.

Tulloch, J. A. (1962). Diabetes Mellitus in the Tropics. Edinburgh and London: E. and S. Livingstone. University College Hospital: Diabetic Clinic (194r). Diabetes and Food Rationing. London: H. K. Lewis \& Co. Ltd.

Walker, J. B. \& Kerridge, D. (1961). Diabetes in an English Community. Leicester: University Press. Wilder, R. M. (1957-8). Perspect. Biol. Med. I, 3.

\section{Patterns and trends in carbohydrate consumption and their relation to disease}

\section{Bу Јонм Yudк In, Nutrition Department, Queen Elizabeth College, University of London}

It is generally held that, for the greater part of the million or more years of his existence, man was a hunter and forager; his diet was largely the bodies of animals he killed or found as carrion, with relatively small amounts of leaves, fruits and roots. Being omnivorous, he could of course sustain himself if necessary with a lower proportion of meat, and a higher proportion of vegetable foods, but by and large his diet was relatively poor in carbohydrate.

With the discovery and development of agriculture some 8 thousand or 10 thousand years ago, the ease of production of carbohydrate-rich foods such as cereals resulted in his diet with few exceptions becoming predominantly carbohydrate, with little fat and with small and often minimal amounts of protein. The only exceptions are 